\section{Genotype Adoption in Processing Sweet Corn Relates to Stability in Case Production}

\author{
Martin M. Williams II ${ }^{1}$ \\ Global Change and Photosynthesis Research, U.S. Department of \\ Agriculture - Agricultural Research Service, 1102 South Goodwin Avenue, \\ Urbana, IL 61801
}

Additional index words. cultivar adoption, environmental index, industrial yield, stability analysis, yield stability, Zea mays

\begin{abstract}
Yield stability (simply "stability") is a crop genotype's performance over a range of environmental conditions, such that a specific genotype may be less sensitive to environmental change (i.e., above-average stability) or more sensitive to environmental change (i.e., below-average stability) relative to other genotypes. The ideal genotype for most crops is believed to have both above-average yield and above-average stability. The objective of the study was to determine the pattern of genotype adoption and use of processing sweet corn in relation to yield and stability. I hypothesized that if yield and stability influence decision-making on genotype choice, then differences among commercial genotypes in such traits would relate to the pattern of adoption and use of those genotypes. Stability analyses of ear mass and case production were conducted on processing sweet corn genotypes grown in varied environments of the United States' Upper Midwest and Pacific Northwest. Yield and stability of the 12 most tested genotypes were then related to the extent of their adoption and use by a sweet corn processing company over a 20-year period. Although some genotypes exhibited above-average yield or above-average stability, data revealed there was no evidence of both traits in individual genotypes currently used in processing sweet corn. Adoption of genotypes with below-average yield or stability was less than other genotypes. Genotype adoption pattern of case production showed the greatest proportion of adoption of above-average stability genotypes. Stable case production across all environments is a more important trait in a genotype to the sweet corn processor than a genotype with record yields under favorable conditions. This conclusion is consistent with the industry's need to have a predictable level of performance in the processing facility, through which all raw product must flow, on a daily basis for the about three-month window of harvest in the northern United States.
\end{abstract}

Yield stability refers to a crop genotype's performance over a range of environmental conditions. The predominant agronomic concept of yield stability, hereafter called simply "stability," is that a genotype's yield changes in a predictable manner across an environmental gradient (Becker and Leon, 1988). A genotype's stability is measured in relation to other genotypes, such that the genotype of interest may be less sensitive to environmental change (i.e., above-average stability) or more sensitive to environmental change (i.e., below-average stability) relative to other genotypes. The ideal genotype for most crops

Received for publication 10 Oct. 2017. Accepted for publication 2 Nov. 2017.

I express sincere gratitude to the anonymous processing company for providing the datasets used in this research.

Mention of a trademark, proprietary product, or vendor does not constitute a guarantee or warranty of the product by the U.S. Department of Agriculture and does not imply its approval to the exclusion of other products or vendors that also may be suitable.

${ }^{1}$ Corresponding author. E-mail: martin.williams@ ars.usda.gov.
Processing sweet corn is grown under contract whereby the processing company determines the genotype for each field contracted. Therefore, genotype adoption in processing sweet corn is driven by the processor, not the grower. Furthermore, there are distinctly different ways to quantify "yield" of processing sweet corn. Contract growers are compensated for mass of unhusked ears per unit area, hereafter called ear mass. Case production is the number of cases of canned sweet corn produced per hectare. Therefore, although ear mass determines gross profit margin to the grower, case production accounts for gross profit margin to the sweet corn processor (Williams, 2014).

Yield stability of sweet corn is unknown. Commercial sweet corn genotypes vary in tolerance to several stresses, including diseases (Pataky et al., 2011), herbicides (Nordby et al., 2008), and weed interference (So et al., 2009). More recently, differential tolerance to plant population density has been reported among sweet corn genotypes grown for processing (Williams, 2012). Based on surveys of growers' fields, Williams (2012) found that density-tolerant genotypes were being under-planted. Multiple lines of evidence indicate sweet corn yield could be increased by growing density-tolerant genotypes at higher plant densities than currently done (Williams, 2012, 2015). Undoubtedly, various factors affect adoption of a specific genotype, including ease of growing, harvesting, and processing. Conceivably, if yield and stability influence processors' decisionmaking on genotype choice, then differences among commercial genotypes in such traits would relate to the pattern of adoption and use of those genotypes.

The objective of the study was to determine the pattern of genotype adoption and use of processing sweet corn in relation to yield and stability. The following hypotheses were tested: 1) adoption and use of genotypes with below-average yield or stability will be less than other genotypes, 2) the most widely used genotypes will show above-average yield or stability, and 3) above-average stability is a more important trait in a genotype than above-average yield.

\section{Materials and Methods}

To protect the confidentiality of parties who provided data for this research, details regarding locations and genotypes will be limited to only those aspects essential to addressing the aforementioned hypotheses.

Genotype trials. Genotype trials were placed in locations representative of the major processing sweet corn production regions of the United States, namely the Pacific Northwest and Upper Midwest. Production environments in the Pacific Northwest are characterized by a cold semiarid climate and center pivot irrigation. Production environments in the Upper Midwest are characterized by a warm-summer or hot-summer humid continental climate. Generally in the 
Midwest, fine-textured soils are rainfed and coarse-textured soils are irrigated.

Genotype trials were conducted from 2004 to 2015 . Each year, trials were planted over the wide range of planting dates common to processing sweet corn production (Table 1). In the Upper Midwest, planting dates ranged from 5 May to 1 July. In the Pacific Northwest, planting dates ranged from 31 Mar. to 19 June. Production practices, including seeding rate, fertilizer application, and pest management, were standard to commercial production at each locale.

The experimental protocol was designed as a randomized complete block with three replications. Experimental units (i.e., plots) measured $3.0 \mathrm{~m}$ wide (four rows on $76-\mathrm{cm}$ row spacing) by $9.2 \mathrm{~m}$ long. Treatments consisted of genotypes of shrunken 2 (sh2) processing sweet corn. On average, 23 genotypes were included per trial; however, not all genotypes were present in every trial. Only the 12 most commonly tested genotypes in the present study are reported. Consistent with previous stability research, genotypes were tested in 15 or more environments (Hildebrand and Russell, 1996; Mohammed et al., 2016). All genotypes were developed for main-season production and ranged in maturity from 78.1 to $87.7 \mathrm{~d}$.

Genotypes were harvested at $76 \%$ kernel moisture. Plots were hand harvested from the center two rows of each plot, $6 \mathrm{~m}$ in length. Ears were then husked using a husking bed, and fresh kernels were cut from the cob with an industry-grade hand-fed corn cutter. Both critical measurements of crop yield were recorded; namely, ear mass and case production. Ear mass was total mass of unhusked ears, reported in $\mathrm{Mt} \cdot \mathrm{ha}^{-1}$. Case production was number of cases of canned sweet corn produced per hectare, where each case represents $6.13 \mathrm{~kg}$ of fresh kernel mass.

Stability analysis. Several statistical methods for evaluating stability have been developed, including univariate and multivariate models (Gauch, 2006; Kang, 1993). Several univariate models have been found to measure the same aspect of stability (Dia et al., 2016), whereas multivariate models are particularly useful in determining genotypes most suitable for specific environments (Mohammed et al., 2016). Regardless of the specific method, analyses of both yield (means) and stability (variances) are more informative than individual statistics (Dia et al., 2016). Because the focus of this research was on the pattern of genotype adoption and use, we chose a standard analytical approach that directly quantified genotype stability.

Regression analysis was used to calculate stability of the 12 genotypes. The procedure calculates an environmental yield index as the mean yield of all genotypes (i.e., population mean) in each environment (Finlay and Wilkinson, 1963). The stability parameter $\left(b_{i}\right)$ is the slope of a linear regression of the yield of a genotype across the environmental yield index. Therefore, the average $b_{i}$ of all genotypes is 1.00 (i.e., average sensitivity to environmental change). A genotype with $b_{i}$ significantly greater than 1.00 has belowaverage stability (i.e., more sensitive to environmental change than the population), whereas a genotype with $b_{i}$ significantly less than 1.00 has above-average stability (i.e., less sensitive to environmental change than the population). In addition, genotype means were calculated and differentiated from the mean of environments in which each genotype was tested based on two sample $t$ tests, such that each genotype's yield was determined to be below-average, average, or above-average. Analyses were performed in SYSTAT 13.0 (SYSTAT Software Inc., Chicago, IL).

Genotype adoption. Genotype adoption was determined using a private sweet corn production dataset of an anonymous processing company for the period 1996-2015. The dataset included 14,775 fields throughout the Upper Midwest and Pacific Northwest. Total area for this period represented 328,000 ha. Records for each field included the genotype and number of hectares planted. For each genotype, the production dataset was queried to determine the number of fields and hectares planted over the period of time that genotype was used (Table 2).

The frequency distribution of both yield and stability for the 12 genotypes was assigned to a contingency table for aboveaverage, average, and below-average responses. Pattern of genotype adoption and use was

Table 1. Planting dates and years of genotype trials at three locations representative of processing sweet corn production in the United States.

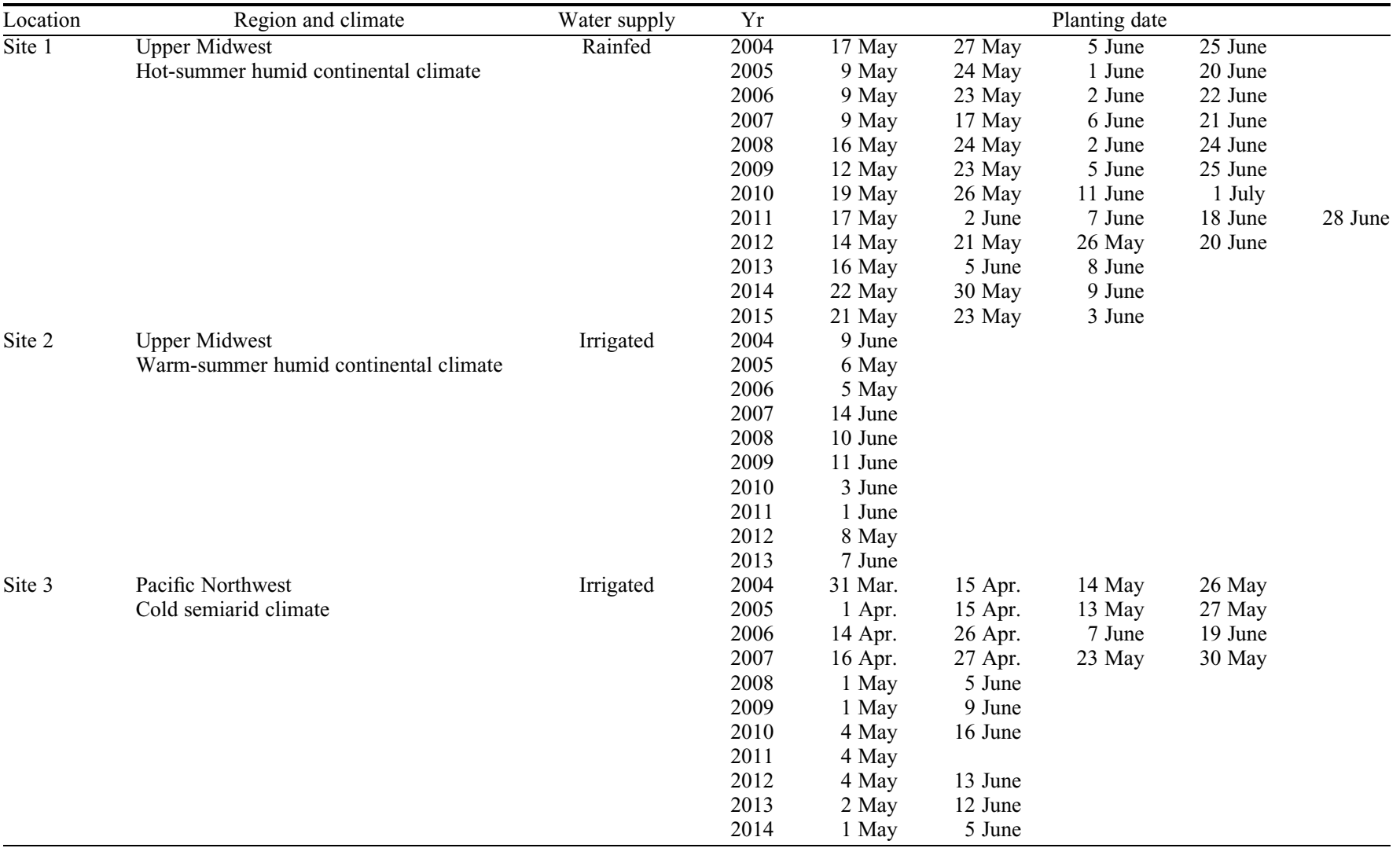


Table 2. Year of first use, year of last use, and mean number of fields per year the processor used the genotype commercially.

\begin{tabular}{|c|c|c|c|}
\hline Genotype & $\begin{array}{l}\text { Yr of } \\
\text { first use }\end{array}$ & $\begin{array}{c}\text { Yr of } \\
\text { last use }\end{array}$ & $\frac{\text { No. fields/yr }}{\text { No./yr }}$ \\
\hline Code1 & 2002 & 2006 & 11 \\
\hline Code 2 & 2008 & 2015 & 5 \\
\hline Code 3 & 2005 & 2015 & 147 \\
\hline Code 4 & 2009 & 2009 & 1 \\
\hline Code 5 & 2007 & 2015 & 15 \\
\hline Code 6 & 2004 & 2007 & 19 \\
\hline Code 7 & 2008 & 2015 & 32 \\
\hline Code 8 & 1996 & 2015 & 232 \\
\hline Code9 & 2009 & 2015 & 24 \\
\hline Code 10 & 2001 & 2011 & 38 \\
\hline Code 11 & 2005 & 2006 & 6 \\
\hline Code 12 & 2005 & 2015 & 4 \\
\hline
\end{tabular}

determined by relating yield and stability of the 12 genotypes from trials to their observed use (cumulative hectares planted) in contract growers' fields. The test of equality of two proportions was used to test hypotheses about genotype adoption and use at $\alpha=$ 0.05 (Agresti, 2007).

\section{Results}

Ear mass. Nine of the 12 genotypes had a mean ear mass comparable with the population (Fig. 1). Genotype Code6 showed below-average ear mass at $18.0 \mathrm{Mt} \cdot \mathrm{ha}^{-1}$. By contrast, genotypes Code 4 and Code 5 showed above-average ear mass at 23.6 and 23.8 Mt.ha ${ }^{-1}$, respectively.

Nine of the 12 genotypes had stability in ear mass comparable with the population (Fig. 1). Ear mass of genotype Code9 was more sensitive to environmental change than the population as evidenced by belowaverage stability in ear mass $\left(b_{i}=1.14\right)$. By contrast, ear mass of genotypes Code10 and Code11 was less sensitive to environmental change than the population as evidenced by above-average stability in ear mass $\left(b_{i}=0.71\right.$ and 0.74 , respectively).

Case production. Eleven of 12 genotypes had a mean case production comparable with the population (Fig. 2). Genotype Code5 showed above-average case production at 1449 cases/ha.

Only a single genotype differed from the population for stability in case production (Fig. 2). Stability in case production for genotype Code8 $\left(b_{i}=0.79\right)$ showed the genotype was less sensitive to environmental change than the population.

Genotype adoption and use. Although the germplasm from genotype trials reported here did not account for every production field, the germplasm represented most of the area planted. For instance, the 12 genotypes in this study accounted for $77.4 \%$ of all hectares for the period 1996-2015. Genotypes were not adopted and used equally.

One-half of genotypes adopted for field production showed average ear mass and average stability in ear mass in genotype trials. For instance, six genotypes had both average ear mass and average stability in ear mass, accounting for $64.0 \%$ of hectares planted (Table 3). Four genotypes had either above-average ear mass or ear mass stability, yet in combination accounted for only $8.7 \%$ (i.e., $4.2+4.5$ ) of hectares planted. Two genotypes showed below-average ear mass or ear mass stability in genotype trials, and in combination accounted for only $4.6 \%$ (i.e., $3.5+1.1)$ of hectares planted.

A different pattern of adoption and use was observed for case production compared with ear mass. The 10 genotypes with both average case production and stability in case production in genotype trials were planted on $42.0 \%$ of hectares (Table 3). The single genotype with above-average stability in case production was adopted on $31.2 \%$ of hectares. There was no evidence of adoption of genotypes with below-average case production or below-average stability in case production.

\section{Discussion}

At the time of this research, the 12 genotypes reported in this study represent some of the most popular sh2 processing sweet corn genotypes in North America. Although 12 genotypes is a small sample size compared with field corn, the sweet corn industry as a whole is much smaller. For instance, although the United States dominates global production of sweet corn for consumption and seed, the area of production is $\approx 1 \%$ of field corn. Currently there are 10 major sweet corn breeding programs in North America, and seven of the programs developed the genotypes tested here. University of Illinois sweet corn evaluations from 1984 to 2010 had $\approx 100$ to 600 genotype entries each year; however, most of the entries were not yet commercialized, less than $80 \%$ were $s h 2$ endosperm mutants, and most entries were developed not for processing but for the fresh market (Pataky et al., 2011). Coupled with the fact that growers and processors tend to grow proven genotypes with known flaws rather than growing new genotypes whose deficiencies have not yet been discovered (a phenomenon called "hybrid inertia"; Marshall and Tracy, 2003), the genotypes in this study are believed to broadly reflect yield and stability of processing sweet corn in North America.

While yield varies among processing sweet corn genotypes, so does stability. One-half or more of the 12 genotypes were average for both yield and stability. Not a single genotype displayed both aboveaverage yield and stability for ear mass or case production. High yield and high stability do not appear to be mutually exclusive in field corn (Tollenaar and Lee, 2002). The same would be assumed of sweet corn; however, the present research fails to provide clear evidence of both high yield and high stability in widely used $s h 2$ processing genotypes.

Results support hypothesis no.1 that adoption and use of genotypes with belowaverage yield or stability was less than other genotypes. Two genotypes had belowaverage ear mass or ear mass stability and accounted for only $4.6 \%$ of planted hectares (Table 3). There were no genotypes with below-average case production or stability in case production. The general objective of any plant breeding program is to develop a genotype improved in some way from the one it is replacing and at least equal in all other respects. For sweet corn, stability over seasons and environments is desired (Tracy, 1993). Given the long history of sweet corn improvement in the United States (Huelson, 1954), it is unlikely new genotypes with relatively poor yield or stability would find success.

Results failed to support hypothesis no.2 that the most widely used genotypes would show above-average yield or stability (Table 3). For ear mass, genotypes with simply average yield and stability dominated planted hectares. Why? It is possible the infrequent adoption of high-yielding or exceptionally stable germplasm is because the sweet corn industry has limited access to such germplasm that must also meet minimum requirements for other important traits. Depending on the yield metric, high-yielding or highly stable genotypes represented at most $1 / 3$ of the tested lines. The highest yielding genotype across both yield measures (e.g., Code5) was poorly adopted, suggesting factors other than yield and stability limited the usefulness of that genotype. Several agronomic traits are vitally important in the development of processing sweet corn, including uniformity of maturity, adaptation to machine harvest, processing plant metrics, canned quality, and ability to produce seed (Tracy, 1993).

Hypothesis no. 3 stated above-average stability is a more important trait in a genotype than above-average yield. Analysis of case production strongly supported hypothesis no.3. The single genotype with above-average stability for case production (genotype Code8) was the most widely adopted cultivar. Genotype Code8 was adopted on $31.2 \%$ of hectares. Such high adoption of a single genotype over a 20 -year period is noteworthy. By contrast, genotypes with above-average stability in ear mass appeared to be adopted similarly to genotypes with above-average ear mass. Case production accounts for more gross profit margin to the processor than ear mass (Williams, 2014), making case production the more robust yield metric with regard to economic decisions made by the processor.

Above-average stability in case production appears more important to the sweet corn processing industry than above-average yield. Sweet corn must be harvested in a relatively narrow window of time (i.e., 13 d) to maintain sufficient quality for human consumption (Tracy, 1993). Processing facilities have limited ability to handle surplus ears in a timely fashion, yet are also expensive to operate at a level below their capacity. The industry uses several tactics to provide a predictable supply of ears to the processing facility for the duration of the harvest season, 

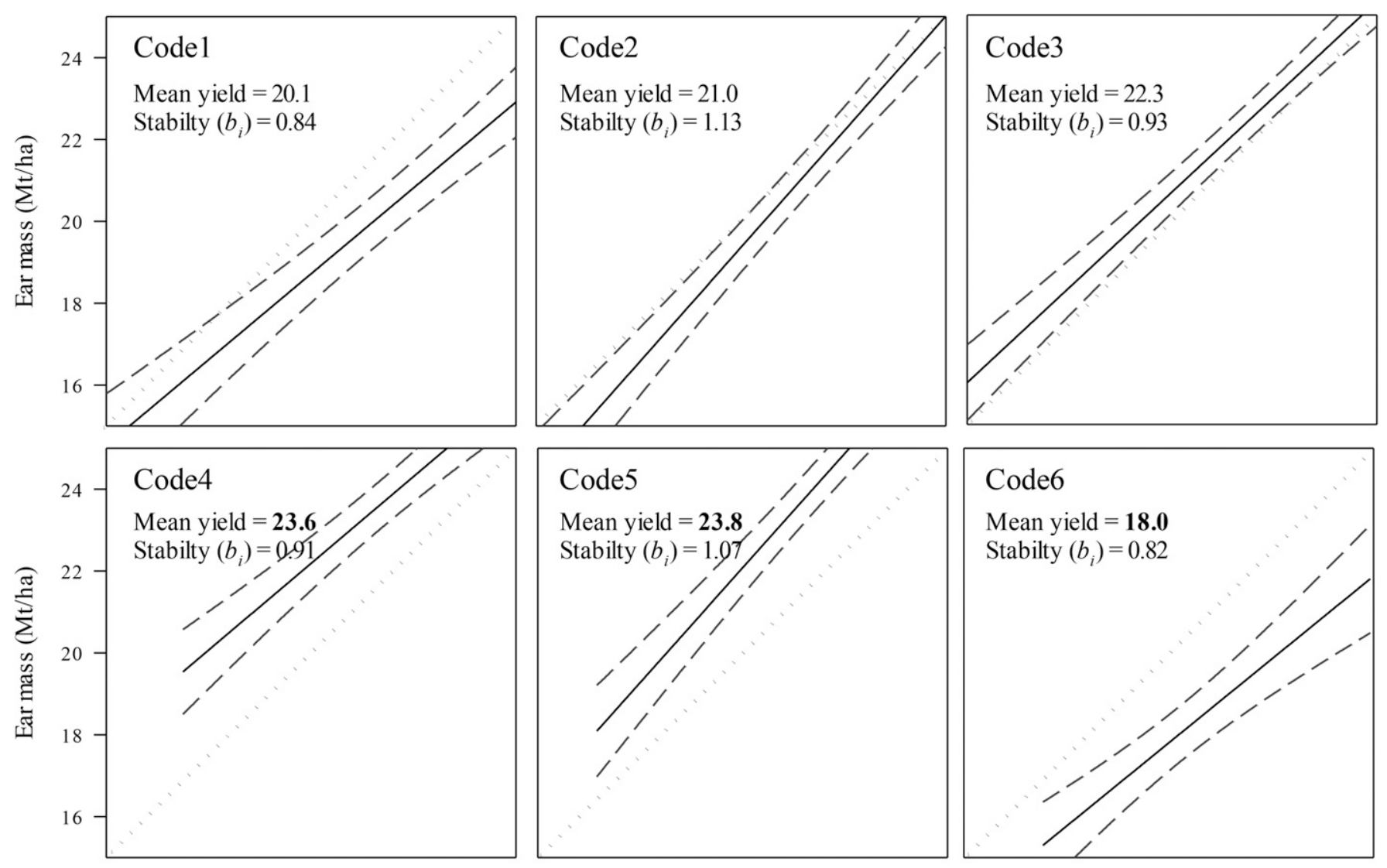

\section{Code6}

Mean yield $=\mathbf{1 8 . 0}$

Stabilty $\left(b_{i}\right)=0.82$
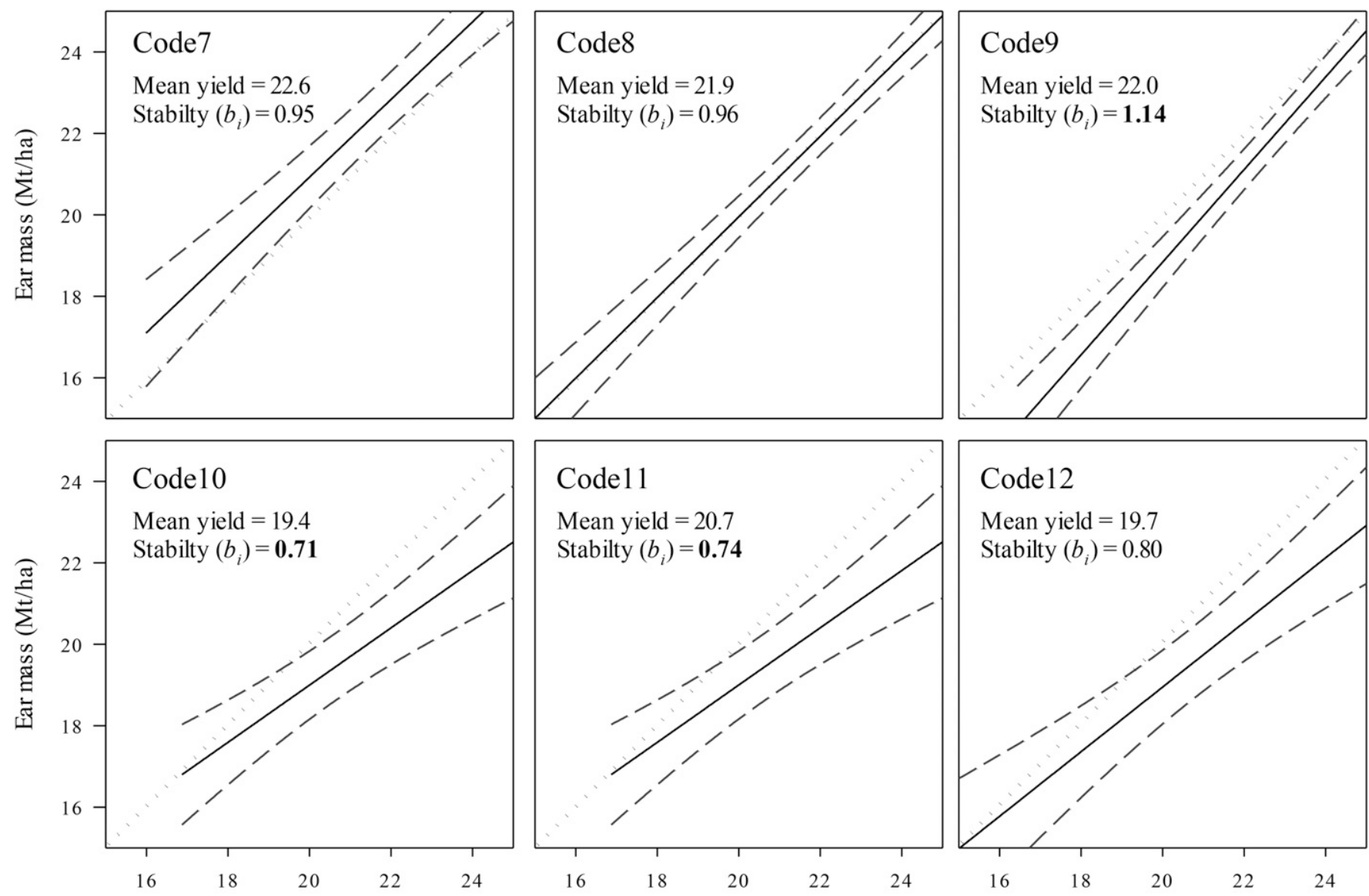

Environmental index (Mt/ha)

Environmental index (Mt/ha)

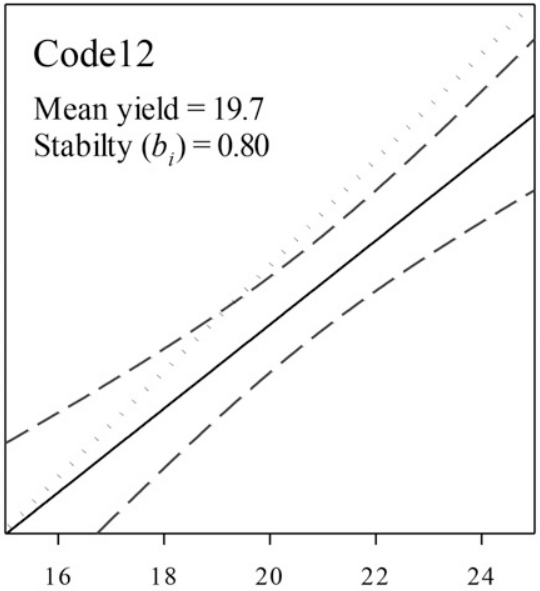

Environmental index (Mt/ha)

Fig. 1. Ear mass response of 12 processing sweet corn genotypes (Code1 to Code12) to environmental index (i.e., mean yield of all genotypes in each environment). Genotype yield estimates in boldface type are significantly different from mean ear mass across genotypes $\left(21.8 \mathrm{Mt} \cdot \mathrm{ha}^{-1}\right)$ based on two sample $t$ tests. Genotype stability estimates in boldface type are significantly different from mean stability across genotypes $\left(b_{i}=1.00\right.$; illustrated as dotted line $)$ based on linear regression analysis. Dashed lines represent $95 \%$ confidence intervals of regression estimates. 

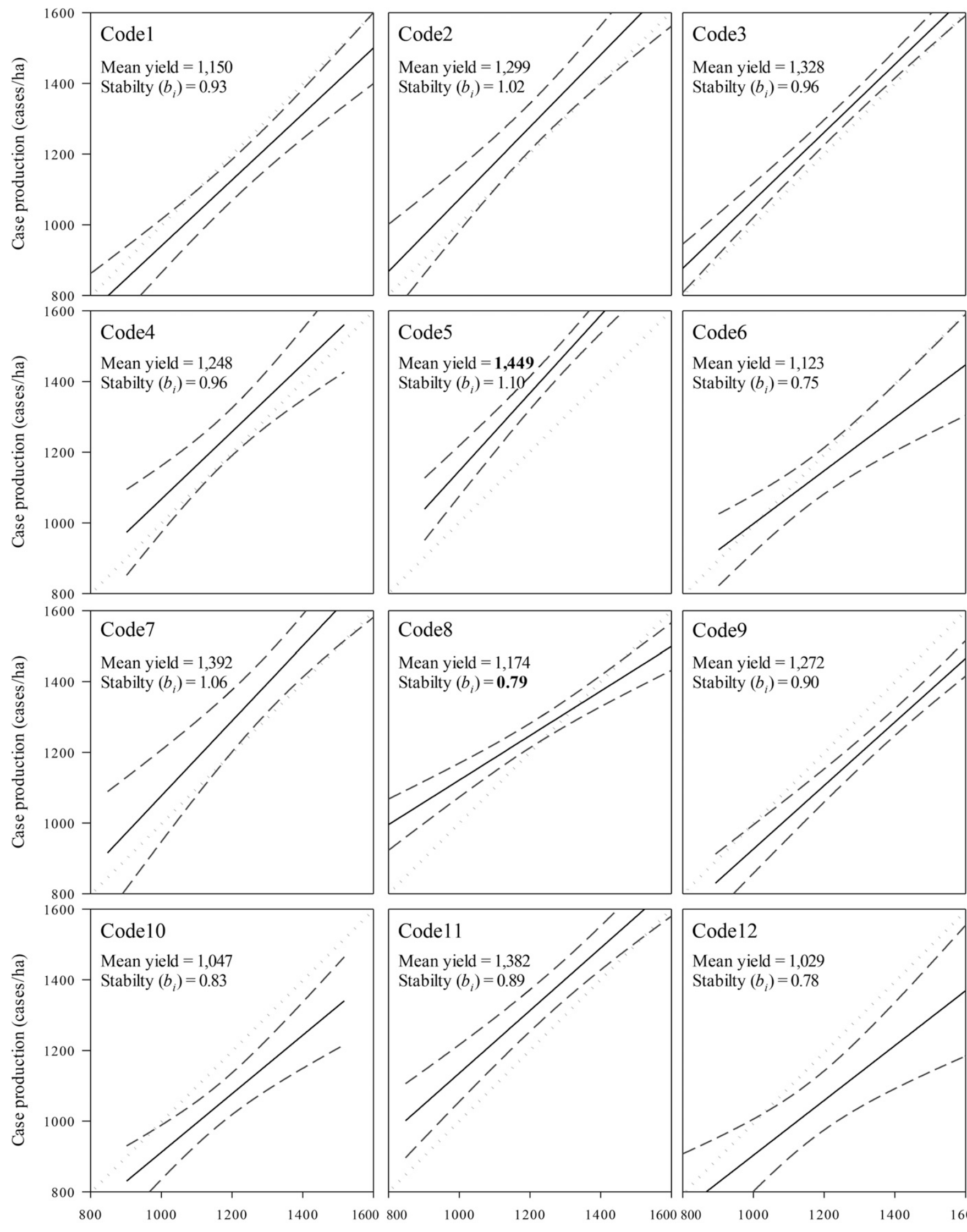

Environmental index (Cases/ha)
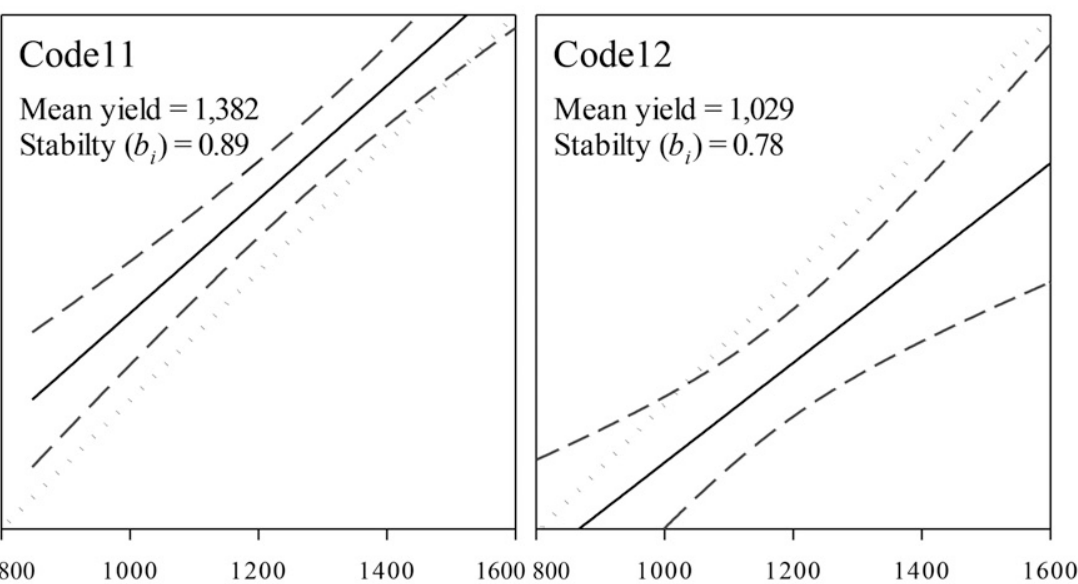

Environmental index(Cases/ha)

Environmental index (Cases/ha)

Fig. 2. Case production response of 12 processing sweet corn genotypes (Code1 to Code12) to environmental index (i.e., mean yield of all genotypes in each environment). Genotype yield estimates in boldface type are significantly different from mean case production across genotypes (1230 cases/ha) based on two sample $t$ tests. Genotype stability estimates in boldface type are significantly different from mean stability across genotypes $\left(b_{i}=1.00 ;\right.$ illustrated as dotted line) based on linear regression analysis. Dashed lines represent $95 \%$ confidence intervals of regression estimates. 
Table 3. Pattern of genotype adoption (1996-2015) observed in production fields in relation to mean yield and yield stability of those genotypes from independent genotype trials. Analysis was conducted on measures of processing sweet corn yield, specifically, ear mass and case production. Results are reported in number of genotypes observed and cumulative hectares planted for genotypes with above-average, average, and below-average yield and yield stability. The test of equality of two proportions was used to test null $\left(H_{0}\right)$ and alternate $\left(H_{1}\right)$ hypotheses about genotype adoption based on cumulative hectares planted $(n=77)$.

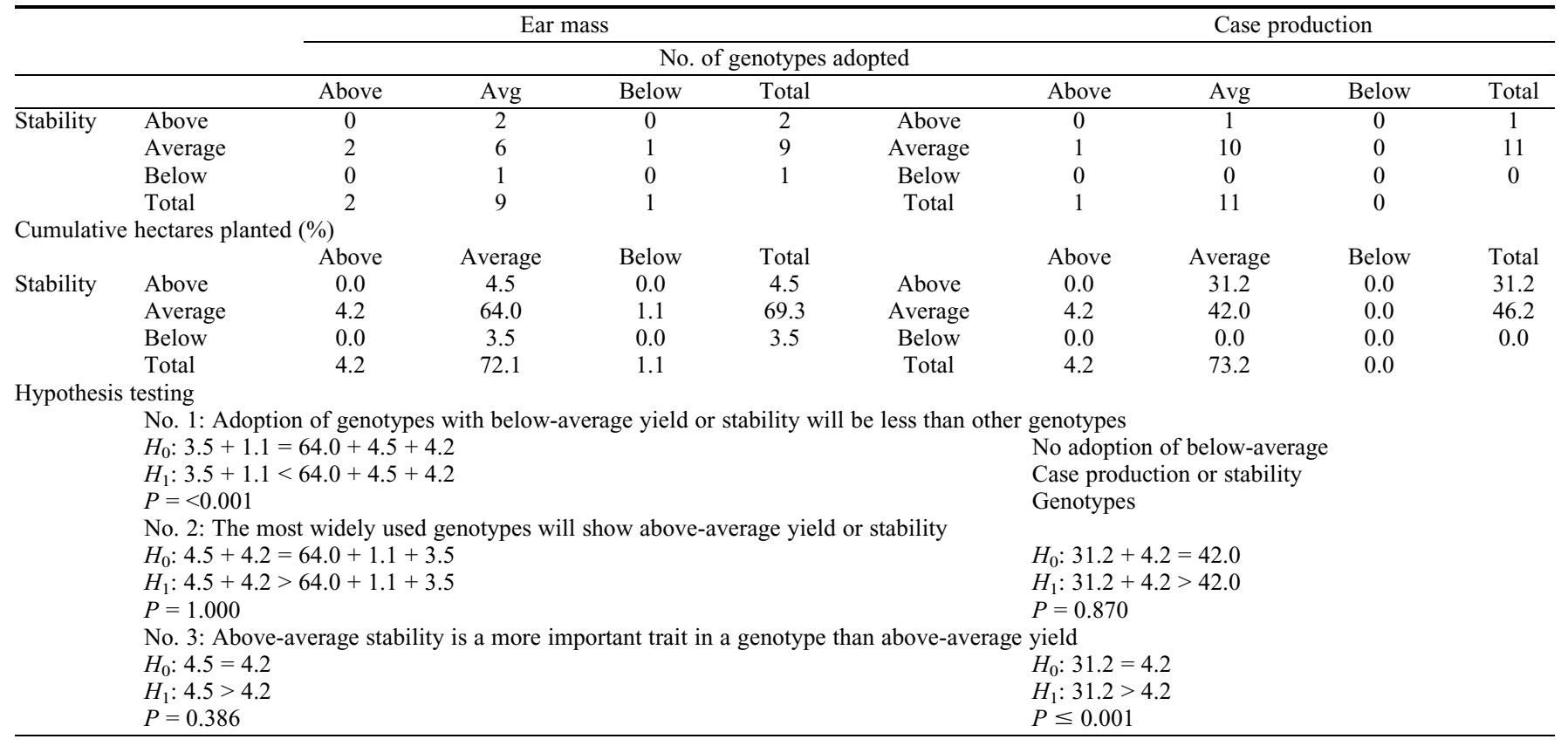

including staggered planting dates, genotype maturity, and field-related parameters including yield potential and crop development rate (Huelson, 1954). Using genotypes that have the least sensitivity to environmental variation (i.e., above-average stability) in case production would be yet another strategy the sweet corn processor could use to reduce variability in processing facility performance. That the single genotype with above-average stability in case production (genotype Code8) accounts for a disproportionally high number of planted hectares is consistent with the realities of the sweet corn processing industry.

The ideal genotype for most crops maintains high yield and high stability over a range of favorable and unfavorable growing conditions. Although some of the most popular sh2 genotypes exhibit above-average yield or above-average stability, there is little evidence of both traits in individual sweet corn genotypes. Breeding for both high yield and high stability in sweet corn may be complicated by the challenges of achieving minimum requirements in other important agronomic and sensory traits. For instance, the consumer alone has expectations regarding kernel appearance, pericarp tenderness, and flavor that cannot be ignored by the sweet corn breeder. The cost of sweet corn phenotyping is considerable compared with field corn, thus limiting genotype evaluation (Tracy, 1993). The lack of adoption of "ideal" genotypes from this research may also reflect the relatively limited yield testing across a range of environments.

Case production and stability of case production of sweet corn genotypes relate to their pattern of adoption and use in the United
States. Processors were not adopting genotypes with below-average case production or stability. Such genotypes would not have been widely tested in genotype trials, likely because the steep cost of genotype evaluation necessitates the rigorous culling of poor-performing genotypes. In the present research, genotype adoption pattern of case production also showed the greatest proportion of adoption of above-average stability genotypes. To the best of our knowledge, this is the first report of how genotype yield and stability relate to genotype adoption and use for any crop.

Stable case production across all environments is a more important trait in a genotype to the sweet corn processor than a genotype with record yields under favorable conditions. In the context of field corn genotype stability described by Tollenaar and Lee (2002), the sweet corn processing industry favors "workhorse" genotypes over "racehorse" genotypes. Workhorse genotypes have above-average stability, in contrast to racehorse genotypes that only yield well in the best environments. This makes sense given the industry's need to have a predictable level of performance in the processing facility, through which all raw product must flow, on a daily basis over an $\approx 3$-month window of harvest in the northern United States. Stability in case production is unlikely to become less of a priority in a climate showing increasing variability in temperature and precipitation.

\section{Literature Cited}

Agresti, A. 2007. An introduction to categorical data analysis. Wiley, Hoboken, NJ.

Becker, H.C. and J. Leon. 1988. Stability analysis in plant breeding. Plant Breeding 101:1-23.
Calderini, D.F. and G.A. Slafer. 1999. Has yield stability changed with genetic improvement of wheat yield? Euphytica 107:51-59.

Dia, M., T.C. Wehner, R. Hassell, D.S. Price, G.E. Boyhan, S. Olson, S. King, A.R. Davis, and G.E. Tolla. 2016. Genotype $\times$ environment interaction and stability analysis for watermelon fruit yield in the United States. Crop Sci. 56:1645-1661.

Finlay, K.W. and G.N. Wilkinson. 1963. The analysis of adaptation in a plant-breeding programme. Austral. J. Agr. Res. 14:742-754.

Gauch, H.G. 2006. Statistical analysis of yield trials by AMMI and GGE. Crop Sci. 46:1488-1500.

Hildebrand, P.E. and J.T. Russell. 1996. Adaptability analysis: A method for design, analysis, and interpretation of on-farm researchextension. Iowa State Univ. Press, Ames, IA.

Huelson, W.A. 1954. Sweet corn. Interscience Publ., New York, NY.

Jensen, S.D. and A.J. Cavalieri. 1983. Drought tolerance in US maize. Agr. Water Mgt. 7:223236.

Kang, M.S. 1993. Simultaneous selection for yield and stability in crop performance trials: Consequences for growers. Agron. J. 85:754-757.

Lobell, D.B., M.J. Roberts, W. Schlenker, N. Braun, B.B. Little, R.M. Rejesus, and G.L. Hammer. 2014. Greater sensitivity to drought accompanies maize yield increase in the U.S. Midwest. Science 344:516-519.

Lu'quez, J.E., L.A.N. Aguirreza'bal, M.E. Aguero, and V.R. Pereyra. 2002. Stability and adaptability of cultivars in non-balanced yield trials: Comparison of methods for selecting 'high oleic' sunflower hybrids for grain yield and quality. J. Agron. Crop Sci. 188:225-234.

Marshall, S.W. and W.F. Tracy. 2003. Sweet corn, p. 537-569. In: P.J. White and L.A. Johnson (eds.). Corn-Chemistry and technology. 2nd ed. Amer. Assn. Cereal Chemists, Inc., St. Paul, MN. Mohammed, Y.A., C. Chen, K. McPhee, P. Miller, K. McVay, J. Eckhoff, P. Lamb, J. Miller, Q. 
Khan, B. Bohannon, M. Knox, and J. Holmes. 2016. Yield performance and stability of dry pea and lentil genotypes in semi-arid cereal dominated cropping systems. Field Crops Res. 188:31-40.

Nordby, J.N., M.M. Williams, II., J.K. Pataky, and D.E. Riechers. 2008. A common genetic basis in sweet corn inbred $\mathrm{Cr} 1$ for cross-sensitivity to multiple cytochrome P450-metabolized herbicides. Weed Sci. 56:376-382.

Padi, F.K. 2007. Relationship between stress tolerance and grain yield stability in cowpea. $\mathrm{J}$. Agr. Sci. 142:431-443.
Pataky, J.K., M.M. Williams, II., J.M. Headrick, C. Nankam, L.J. du Toit, and P.M. Michener. 2011. Observations from a quarter century of evaluating reactions of sweet corn hybrids to disease nurseries. Plant Dis. 95:1492-1506.

So, Y.F., M.M. Williams, II., J.K. Pataky, and A.S Davis. 2009. Principal canopy factors of sweet corn and relationships to competitive ability with wild-proso millet (Panicum milliaceum) Weed Sci. 57:296-303.

Tollenaar, M. and E.A. Lee. 2002. Yield potential, yield stability and stress tolerance in maize. Field Crops Res. 75:161-169.
Tracy, W.F. 1993. Sweet corn, Zea mays L., p. 777-807. In: G. Kalloo and B.O. Bergh (eds.) Genetic improvement of vegetable crops. Pergamon Press, Oxford, UK.

Williams, II., M.M. 2012. Agronomics and economics of plant population density on processing sweet corn. Field Crops Res. 128:55-61.

Williams, II., M.M. 2014. Few crop traits predict variables important to productivity of processing sweet corn. Field Crops Res. 157:20-26.

Williams, II., M.M. 2015. Identifying crowding stress-tolerant hybrids in processing sweet corn Agron. J. 107:1782-1788. 